Artigo

\title{
Antena de Microfita Sobre Substrato de Ferrita de Cobalto
}

Lucas Oliveira de Azevedo ${ }^{[1]}$, Idalmir de Souza Queiroz Junior ${ }^{[2]}$, José Lucas da Silva Paiva ${ }^{[3]}$,Pedro Bruno Nogueira da Silva ${ }^{[4]}$, Isaac Barros Tavares da Silva ${ }^{[5]}$ e Nathan Bezerra Gurgel ${ }^{[6]}$

[1] Universidade Federal Rural do Semiárido; lucasoliveira765@outlook.com

[2] Universidade Federal Rural do Semiárido; idalmir@ufersa.edu.br

${ }^{[3]}$ Universidade Federal Rural do Semiárido; jose.paiva@ufersa.edu.br

${ }^{[4]}$ Universidade Federal Rural do Semiárido; nogueira372@gmail.com

${ }^{[5]}$ Universidade Federal Rural do Semiárido; isaac.barros@ufersa.edu.br

${ }^{[6]}$ Universidade Federal Rural do Semiárido; nathan_gurgel@hotmail.com

Recebido: $14 / 06 / 2020$;

Aceito: 09/08/2020;

Publicado: 11/09/2020.

Resumo: A pesquisa referente a esse artigo é sobre a fabricação de uma antena de microfita com o substrato de um material magnético: a ferrita de cobalto, que foi produzido utilizando a técnica sol-gel. A antena foi simulada através do software Ansys HFFS® para uma visualização inicial. Posteriormente a mesma foi fabricada e seu ganho, perda de retorno e impedância foram medidos. Os resultados mostraram que o substrato de ferrita de cobalto miniaturiza a antena construída, melhorando também a resistência témica e mecânica, mantendo o diagrama de radiação esperado para um substrato não magnético (considerando uma permeabilidade de 1,10).

\section{Palavras-chave: Antena de Microfita, Ferrita de Cobalto, Técnica Sol-Gel}

Abstract: The research regarding to this paper is about the fabrication of a microstrip antenna with substrate of a magnetic material: the cobalt ferrite, that was made using the sol-gel technique. The antenna was simulated via the software Ansys HFFS $\AA$ for an initial visualization. Posteriorly the antenna was fabricated, and its gain, return loss and impedance was measured. The results was shown that the cobalt ferrite substrate miniaturizes the constructed antenna, enhancing also temperature and mechanical resistance, maintaining the radiation pattern expected for a non-magnetic substrate (for the relative magnetic permeability of 1.10).

Key-words: Microstrip Antenna, Cobalt Ferrite, Sol-Gel Technique

\section{INTRODUÇÃO}

Com o desenvolvimento progressivo dos sistemas de telecomunicações e da transmissão de dados sem fio (wireless), tem-se cada vez mais procurado por alternativas diversas para sua implementação. Isto deu origem a novas técnicas e dispositivos, entre eles, antenas com características favoráveis para as diversas aplicações envolvidas [1].

Estruturas como satélites, naves espaciais e sistemas embarcados em geral, prezam por um aproveitamento ótimo do espaço, da forma, do peso e do custo dos seus componentes. Dessa maneira as antenas de microfita se apresentam como uma opção viável para o uso já que são de pequenas dimensões, versáteis, leves e de baixo 
custo [2].

As antenas de microfita podem ser construídas sobre substrato de diversos materiais, os quais determinam várias de suas características entre elas suas dimensões. Entre os materiais possíveis para a construção dessas antenas se encontram as ferritas. Esses materiais possuem a característica de serem magnéticos e são classificados nesse contexto como ferrimagnéticos, ou seja, quando submetidos a linhas de campo magnético externas, seus dipolos magnéticos tendem a se alinhar com o campo imposto [3].

A ferrita de cobalto é conhecida pela sua alta coercividade, alta estabilidade química e térmica, além de sua forte anisotropia magnetocristalina (os campos tendem a se alinhar preferencialmente em algumas direções dentro do material) [4]. É bastante versátil, podendo ser utilizada em materiais absorvedores de energia eletromagnética [5], sistemas magnetoelétricos [6], ímãs permanentes [7], fluidos magnéticos e dispositivos de micro-ondas [8].

No trabalho desenvolvido, foi construída uma antena de microfita com substrato de ferrita de cobalto (CoFe2O4) para transmissão e recepção de micro-ondas. Os dados para a perda de retorno e impedância fora obtidos via medição e comparados com os gráficos obtidos em simulação, onde também foi gerado o gráfico para o ganho 3D (não medido).

\section{MATERIAIS E MÉTODOS}

Neste tópico será mostrada toda a metodologia que foi utilizada para a fabricação do substrato de ferrita.

\subsection{Fabricação da Ferrita de Cobalto}

O processo de fabricação da ferrita de cobalto segue o esquema da Fig. 1.

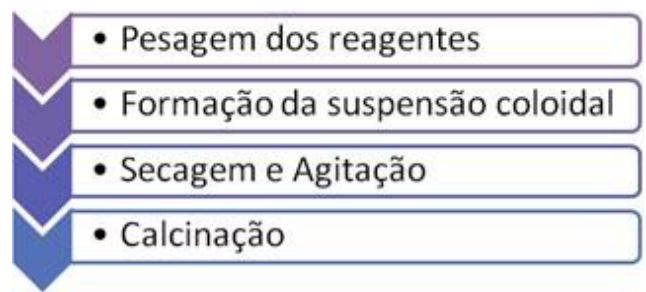

Fig.1. Etapas para a produção da ferrita de cobalto. [9]

Após a realização de cálculos estequimétricos, o resumo da quantidade de cada composto para produção de $1 \mathrm{~g}$ de ferrita de cobalto pode ser visualizado na Tabela 1.

TABELA 1. Quantidade dos compostos necessários para sintetizar $1 \mathrm{~g}$ de ferrita de cobalto. (Autoria própria

2020)

\begin{tabular}{|c|c|}
\hline COMPOSTO & QUANTIDADE \\
\hline Nitrato de cobalto $\left[\mathrm{Co}\left(\mathrm{NO}_{3}\right)_{2}\right]$ & $1,24 \mathrm{~g}$ \\
\hline Nitrato de ferro $\left[\mathrm{Fe}\left(\mathrm{NO}_{3}\right)_{3}\right]$ & $3,45 \mathrm{~g}$ \\
\hline Acido cítrico $\left[\mathrm{C}_{6} \mathrm{H}_{8} \mathrm{O}_{7}\right]$ & $4,00 \mathrm{~g}$ \\
\hline Etilenoglicol $\left[\mathrm{C}_{2} \mathrm{H}_{6} \mathrm{O}_{2}\right]$ & $2,42 \mathrm{ml}$ \\
\hline Água destilada $\left[\mathrm{H}_{2} \mathrm{O}\right]$ & $11,66 \mathrm{ml}$ \\
\hline
\end{tabular}

Após serem pesados em uma balança analítica da marca MARTE, os reagentes foram colocados em um béquer de $600 \mathrm{ml}$, sendo primeiro colocada a água destilada e após isso respectivamente o nitrato de cobalto, o 
nitrato de ferro, o ácido cítrico e o etileniglicol.

Em seguida, a solução foi posta para secar e misturar em um misturador magnético com aquecimento da marca LUCADEMA (Fig. 2) até que a solução obtivesse aspecto gelatinoso. Esse processo foi repetido por vários dias e em temperaturas diferentes de acordo com a necessidade.

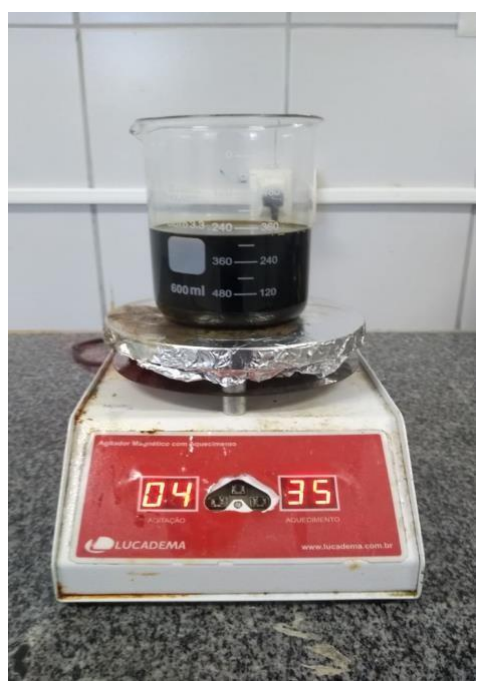

Fig.2. Solução sobre misturador magnético com aquecimento. (Autoria própria, 2020)

Após ter obtido aspecto gelatinoso a solução foi transferida para potes de plástico para secagem ao sol, com a finalidade de evitar causar danos ao béquer (ou sacrificá- lo) ao retirar a ferrita já seca. Depois da secagem ao sol a ferrita obteve o aspecto pastoso como mostra a Fig. 3

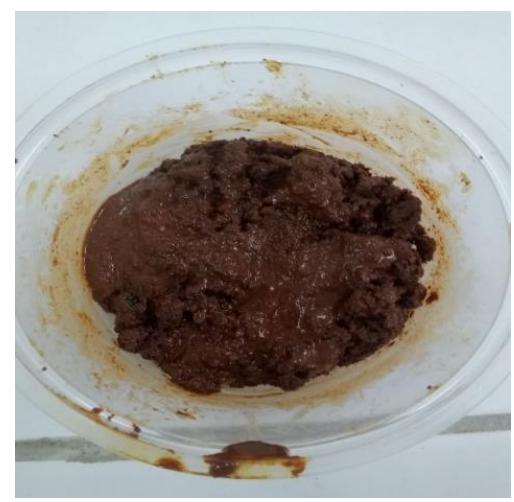

Fig.3. Ferrita após a secagem ao sol. (Autoria própria, 2020)

Para retirar o restante umidade mais rapidamente e de maneira mais eficiente, após a secagem ao sol a ferrita foi levada a uma estufa com circulação de ar da marca TECNAL e foi mantida a $120^{\circ} \mathrm{C}$ por cerca de 4 horas. Após isso a mesma já apresentava aspecto praticamente seco e poroso.

Para a retirada da matéria orgânica restante associada a ferrita devido aos componentes orgânicos etilenoglicol e ácido cítrico, a mesma foi calcinada em um forno mufla da marca JUNG a $400^{\circ} \mathrm{C}$ por cerca de 6 horas, com rampa de $35^{\circ} \mathrm{C}$ até os $400^{\circ} \mathrm{C}$ de $5^{\circ} \mathrm{C}$ /minuto. Após esse procedimento a ferrita já calcinada, com aspecto mais escuro e quebradiço (como pode ser visto na Fig. 4.a) foi macerada para se obter o pó de ferrita, apresentado na Fig. 4.b. 


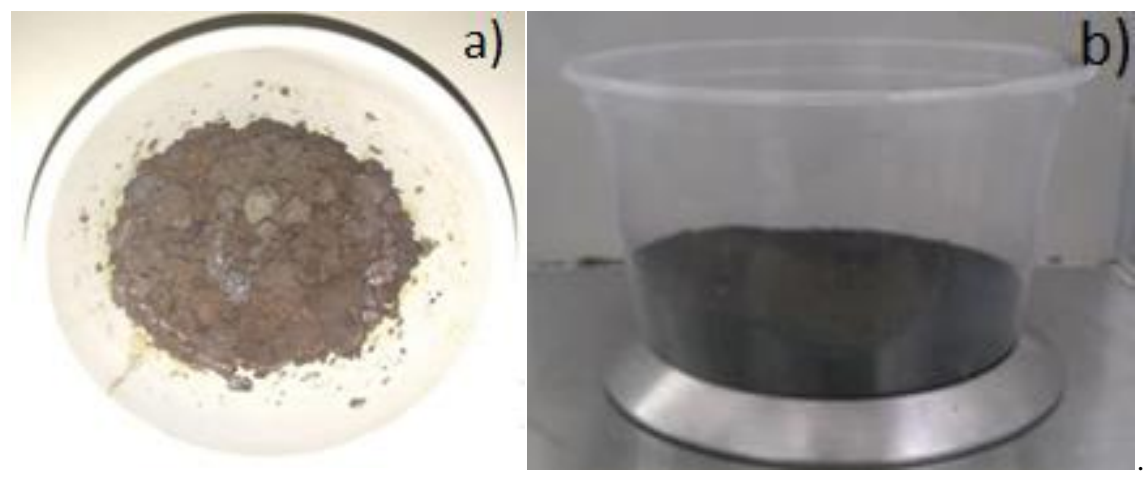

Fig.4. a) Ferrita após a calcinação, b) ferrita após a maceração. (Autoria própria, 2020)

\subsection{Construção da Pastilha Para o Substrato}

O próximo passo para a construção da antena em questão, foi a construção da pastilha que foi utilizada como substrato. Para isso foram utilizadas matrizes de $25 \mathrm{~mm}$ de diâmetro para o pastilhamento do pó de ferrita.

Dessa maneira, uma quantidade de $3,63 \mathrm{~g}$ de ferrita foram colocadas dentro da matriz e a mesma foi submetida a uma força de 2 tonelada-força durante 5 minutos. A prensa utilizada foi uma prensa da marca BONEVAU com capacidade de 10 toneladas, podendo ser visualizada na Fig. 6.

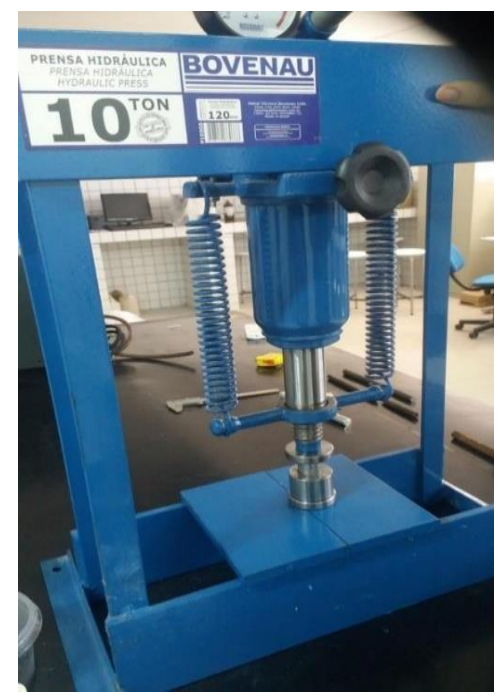

Fig. 6. Prensa utilizada para o pastilhamento da ferrita. (Autoria própria, 2020)

Após a prensagem da ferrita, a pastilha foi levada ao forno mufla para a sinterização, de forma a promover uma maior resistência mecânica da mesma e manter suas moléculas mais unidas, para isso a pastilha foi mantida a $1200{ }^{\circ} \mathrm{C}$ por 6 horas com rampa de $35^{\circ} \mathrm{C}$ até os $1200^{\circ} \mathrm{C}$ de $5^{\circ} \mathrm{C}$ /minuto. $\mathrm{O}$ forno foi o mesmo utilizado na calcinação e pode ser visualizado na Fig. 7. 


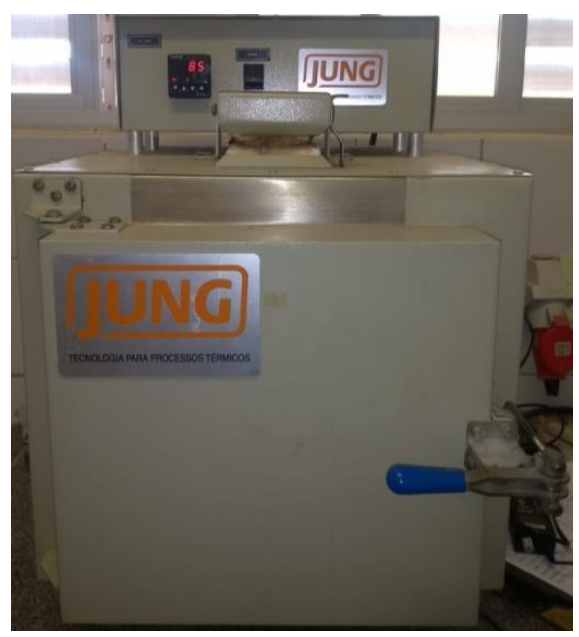

Fig.7. Forno mufla JUNG. (Autoria própria, 2020)

A pastilha obtida ao final do processo pode ser visualizada na Fig. 8, juntamente com a matriz utilizada para sua construção. Observou-se que o diâmetro da pastilha após a calcinação foi reduzido a $19 \mathrm{~mm}$ (uma redução de $6 \mathrm{~mm}$ de diâmetro) e possuia $2 \mathrm{~mm}$ de espessura, metade de seu valor original, indicando maior agregação das moléculas.

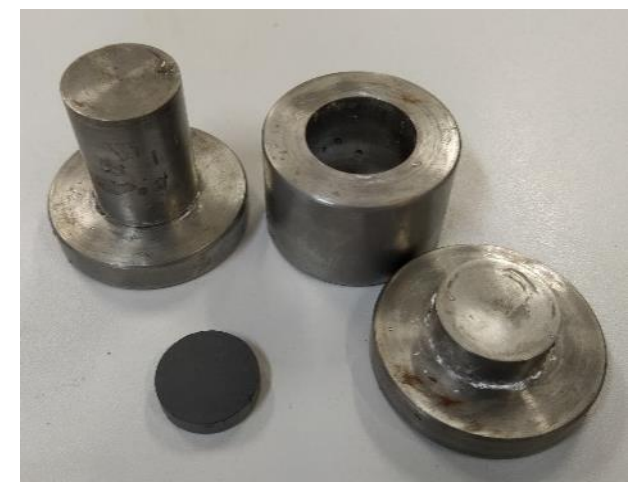

Fig.8. Pastilha já pronta e a matriz utilizada para sua confecção. (Autoria própria, 2020)

3. RESULTADOS

Neste tópico serão mostrados os resultados da simulação feita no software Ansys HFSS® e os resultados obtidos na medição da antena, comparando ambos.

\subsection{Resultados Obtidos na Simulação}

A antena simulada no Ansys HFSS® pode ser visualizada na Fig. 9 abaixo, sendo originalmente projetada para $7 \mathrm{GHz}$, considerando um dielétrico não magnético. 


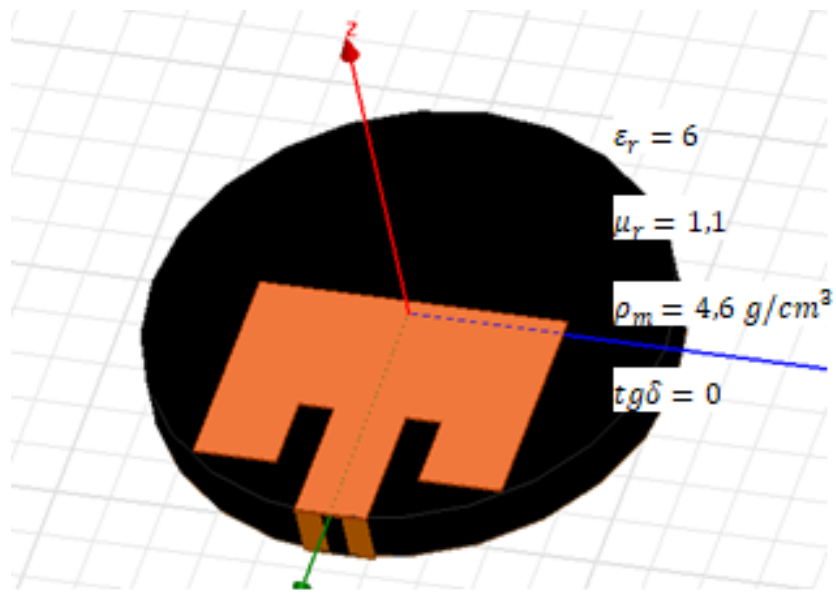

Fig.9. Antena simulada. (Autoria própria, 2020)

Os valores não foram obtidos para a ferrita produzida, mas sim considerados se baseando nos dados do software, de medições para uma outra amostra do mesmo material e da literatura. A permissividade relativa do substrato ( $\varepsilon r)$ foi obtida a partir da medição de uma amostra de ferrita de cobalto produzida por um colega de trabalho, havendo pouca variação desse valor para a largura de banda obtida. Os valores da tangente de perdas $(\operatorname{tg} \delta)$ e densidade de massa $\left(\rho_{\mathrm{m}}\right)$ do substrato são valores sugeridos pelo software para ferritas em geral. O valor da permeabilidade relativa foi obtido através de [10]. Valores de permeabilidade muito próximos de 1,1 para a frequência de $7 \mathrm{GHz}$ também foram encontrados em [5] e [11].

Partindo da simulação, se obteve o diagrama de radiação 3D para o ganho da Fig. 10.

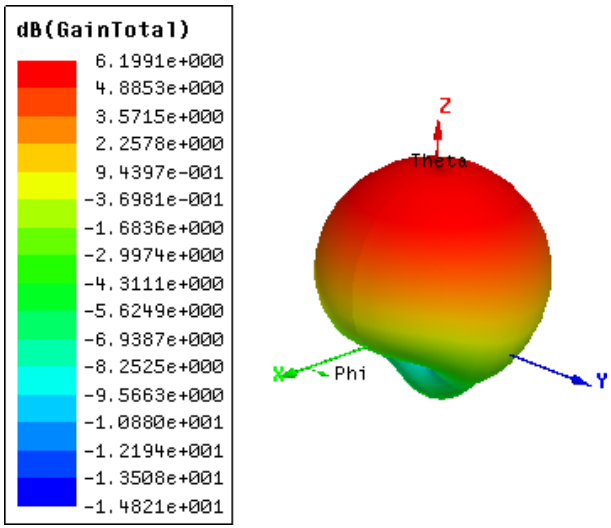

Fig. 10. Diagrama de radiação 3D. (Autoria própria, 2020)

Os diagramas de radiação 2D para o corte longitudinal e transversal são respectivamente mostrados na Fig. 11. 

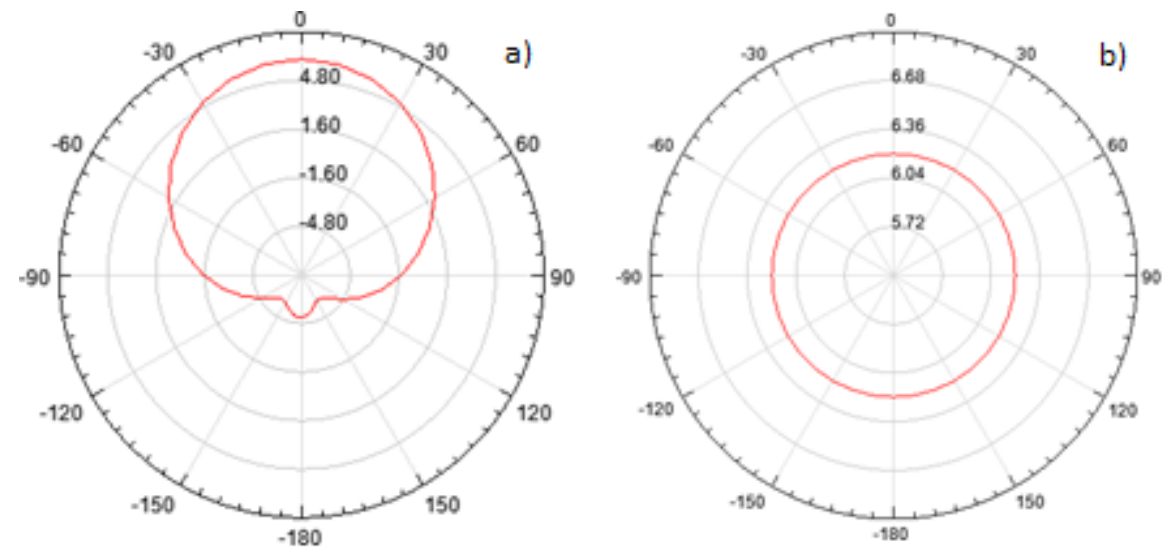

Fig. 11. a) Corte longitudinal do diagrama de radiação, b) Corte transversal do diagrama de radiação. (Autoria própria, 2020)

Os resultados com relação ao diagrama de radiação foi o esperado: radiação broadside com lóbulo único, apresentando valores favoráveis.

O gráfico para a perda de retorno em função da frequência para a antena simulada é o mostrado na

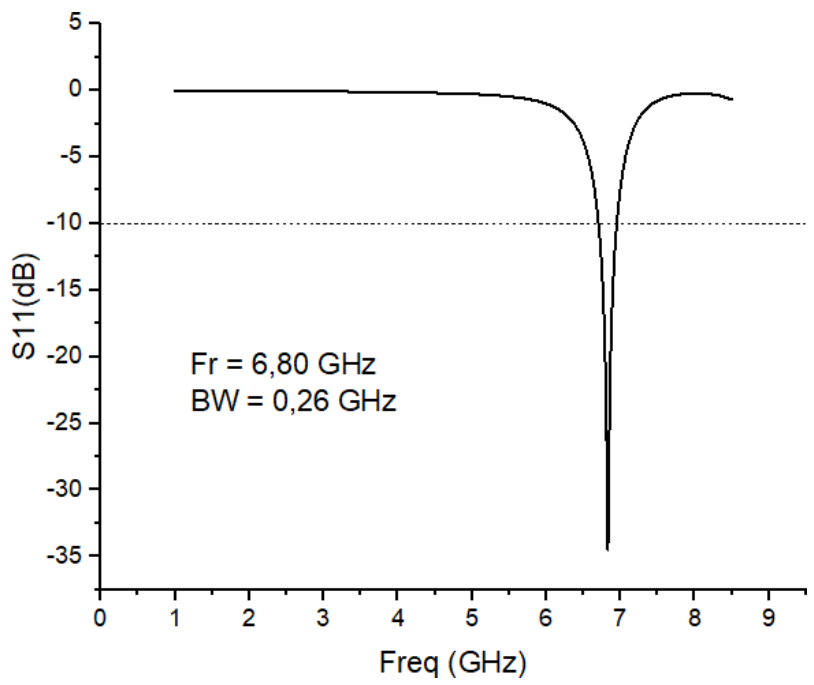

Fig. 13.

Fig. 13. Gráfico de $S_{11}$ x Frequência da antena simulada. (Autoria própria, 2020)

Pode-se observar que houve um deslocamento da frequência de ressonância de $7 \mathrm{GHz}$ para $6,80 \mathrm{GHz}$. Esse resultado já era esperado devido ao fato de que a permeabilidade relativa do substrato é maior do que 1 , levando à miniaturização da antena.

$\mathrm{Na}$ frequência de ressonância o coeficiente de reflexão é de $-35 \mathrm{~dB}$, se obtendo uma largura de banda de $0,26 \mathrm{GHz}$ entre $6,701 \mathrm{GHz}$ e $6,962 \mathrm{GHz}$.

A carta de Smith para a antena simulada pode ser visualizada na Fig. 14 para uma varredura de frequência de 0 a $8,5 \mathrm{GHz}$. 


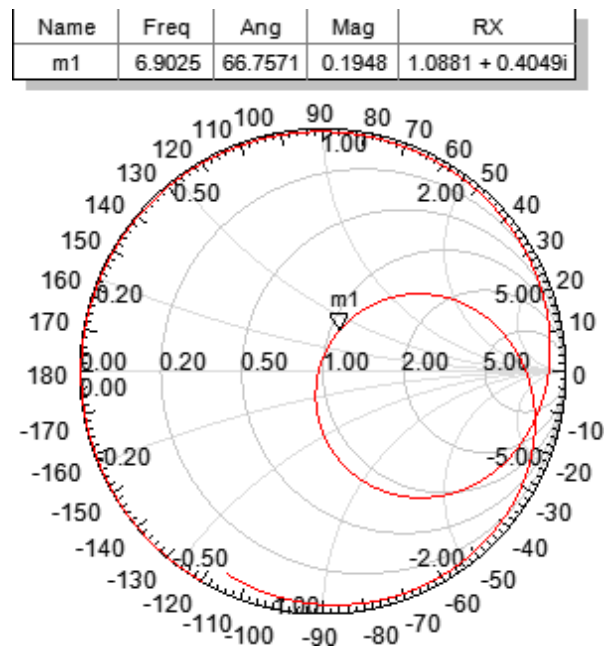

Fig.14. Carta de Smith gerada pelo software HFSS®. (Autoria própria 2020)

Para a frequência de ressonância (ponto m1) a impedância de entrada é de $54,40+\mathrm{j} 20 \Omega$ mostrando um bom ajuste para alimentadores $50 \Omega$.

Na Tabela 3 pode-se visualizar o resumo dos resultados obtidos para a antena simulada.

TABELA 3: Resumo dos resultados para a antena simulada. (Autoria própria, 2020)

\begin{tabular}{|c|c|}
\hline PARÂMETRO & VALOR \\
\hline Frequência de ressonância & $6,8 \mathrm{GHz}$ \\
\hline Largura de banda & $0,26 \mathrm{GHz}$ \\
\hline Ganho máximo & $6,20 \mathrm{~dB}$ \\
\hline Perda de retorno mínima & $-35 \mathrm{~dB}$ \\
\hline Impedância de entrada na ressonância & $54,40+\mathrm{j} 20$ \\
\hline
\end{tabular}

\subsection{Resultados Obtidos na Medição}

A foto tirada da antena medida pode ser visualizada na Fig. 15.

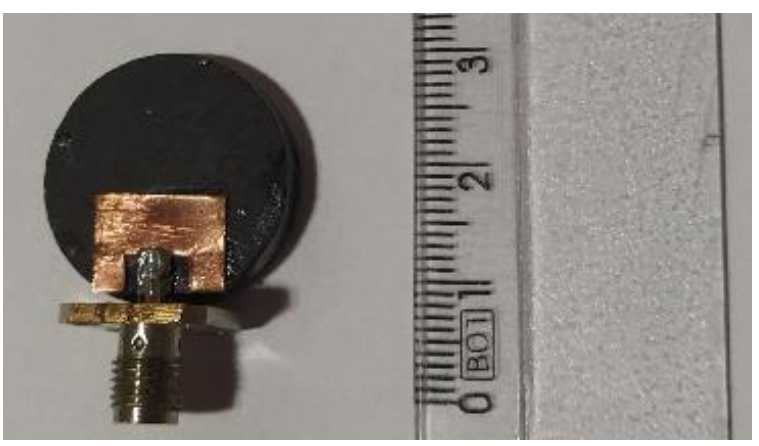

Figura 15: Antena medida. (Autoria própria, 2020) 
Para realizar a medição se utilizou um Vector Network Analyzer da marca RHODE \& SCHWARZ, que pode ser visto na Fig. 16.

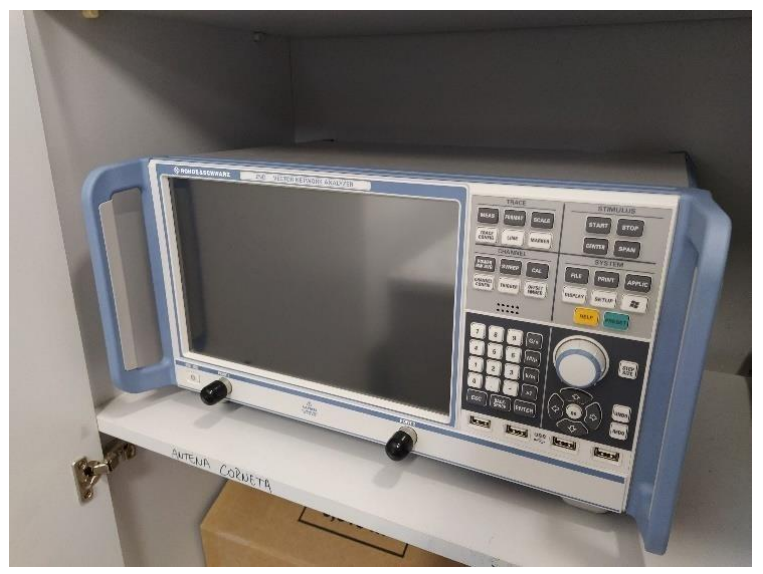

Fig. 16. Vector Network Analyzer utilizado para a medição da antena produzida. (Autoria própria, 2020)

Foram obtidos os dados para a perda de retorno em função da frequência através do VNA e eles foram plotados. O gráfico da perda de retorno pode ser visualizado na Fig. 17.

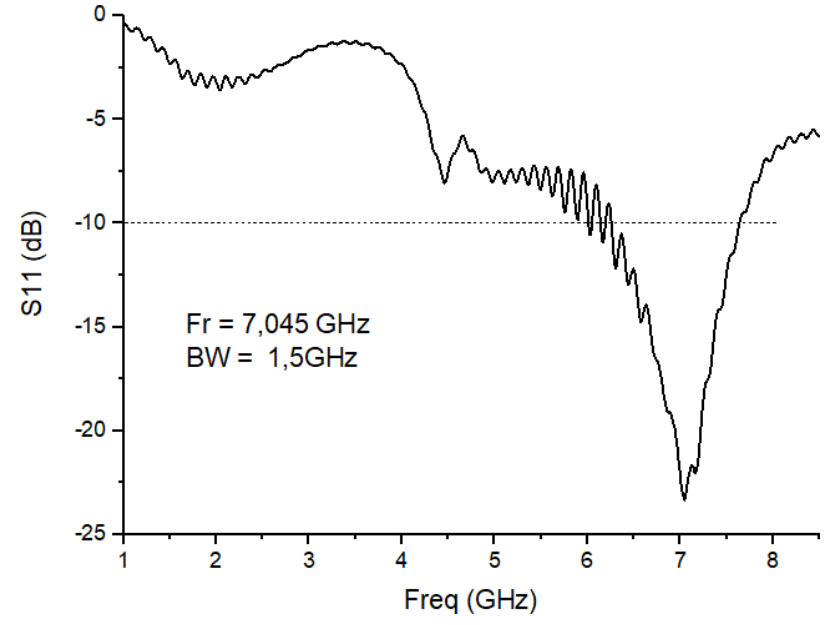

Fig. 17. Gráfico de $S_{11}$ x Frequência da antena medida (Autoria própria, 2020)

Observa-se que a antena ressoa em 7,045 GHz com perda de retorno de -23,30dB obtendo-se também uma largura de banda de $1,5 \mathrm{GHz}$ (entre $6 \mathrm{GHz}$ e 7,5 GHz), valor cerca de seis vezes maior que o obtido via simulação. O deslocamento da frequência de ressonância de volta a 7 GHz que foi obtido no VNA pode ter diversas causas, entre elas o excesso de solda na linha da antena, a proximidade mais do que esperada da permeabilidade magnética do substrato do valor de , erros na confecção do patch e variações na medição da antena devido a imprecisão do equipamento.

A carta de Smith obtida no VNA pode ser visualizada na Fig. 18. 


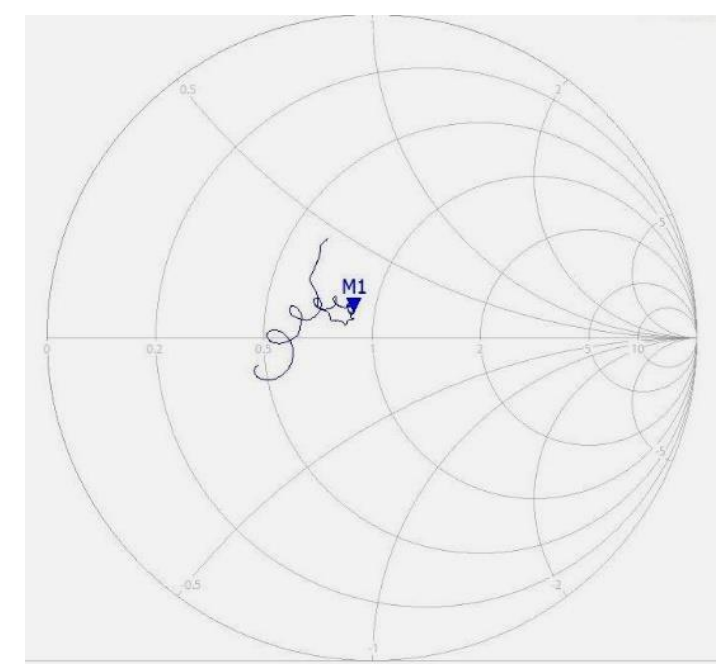

Fig. 18. Carta de Smith obtida no VNA para a antena medida. (Autoria própria, 2020)

Para a frequência de ressonância (ponto M1) a carta de Smith revelou uma impedância de entrada de $44,095+\mathrm{j} 7,16$, sendo um valor coerente com o que era esperado.

$\mathrm{Na}$ Tabela 4 pode-se visualizar os resultados obtidos para a antena medida.

TABELA 4: Resumo dos resultados obtidos na medição. (Autoria própria, 2020)

\begin{tabular}{|c|c|}
\hline PARÂMETRO & VALOR \\
\hline Frequência de ressonância & $7,045 \mathrm{GHz}$ \\
\hline Largura de banda & $1,50 \mathrm{GHz}$ \\
\hline Perda de retorno mínima & $-23,30 \mathrm{~dB}$ \\
\hline Impedância de entrada na ressonância & $44,095+\mathrm{j} 7,16$ \\
\hline
\end{tabular}

\section{CONCLUSÃO}

Neste trabalho foi sintetizado o material magnético ferrita de cobalto $\left(\mathrm{CoFe}_{2} \mathrm{O}_{4}\right)$ para a utilização como substrato em uma antena de microfita. A realização da síntese ocorreu de maneira apropriada e a pastilha feita posteriormente estava em condições adequadas, sem rachaduras e com boa resistência mecânica.

A antena que foi construída, anteriormente, foi projetada e simulada, se obtendo resultados coerentes com o esperado. Posteriormente a antena foi construída e medida, se obtendo resultados um pouco divergentes com relação ao obtido via simulação para a frequência de ressonância e impedância de entrada, mas ainda com um bom ajuste. Neste caso, foi obtida uma maior largura de banda, entretanto, uma maior perda de retorno, havendo o deslocamento da frequência de $6,8 \mathrm{GHz}$ (esperado) para $7 \mathrm{GHz}$ (frequência de ressonância de projeto da antena).

\section{REFERÊNCIAS}

[1] Silva, J.L. Estudo do Comportamento de Antena de Microfita com Substrato Metamaterial. Dissertação (Mestrado), UFERSA, Mossoró, 2015.

[2] Balanis, C. Mocrostrip Antennas. Anthenna Theory: analysis and design, 3. ed.; Hoboken: John Wiley \& Sons, Inc., 2005.p. $722-775$.

[3] Shinde, T.J.; Gadkari, A.B.; Vasambekar, P.N..Magnetic properties andcation distribution study of nanocrystalline ni-zn ferrites. Journal Of Magnetism And Magnetic Materials 2013, v. 333. 
[4] Junior, J. V. Síntese por Sol-Gel de Ferrita de Cobalto e sua Caracterização Microestrutural e de Propriedades Magnéticas. . Dissertação de Mestrado, UFRGS, Porto Alegre, 2015.

[5] Wan, G. et al. The Fabrication and High-Efficiency Electromagnetic Wave Absorption Performance of CoFe/C Core- Shell Structured Nanocomposites. Nanoscale Research Letters 2018.

[6] Comes, R. et al. Directed Self-Assembly of Epitaxial CoFe2O4- BiFeO3 Multiferroic Nanocomposites. Nano Letters 2012, p. 2367-2373.

[7] Kurian, M. et al. Structural,magnetic, and acidic properties of cobalt ferritenanoparticles synthesised by wet chemical methods. J Adv Ceram. 2015;4:199-205.

[8] Perdomo, C. P. F. et al. Effect of the $\mathrm{CoFe} 2 \mathrm{O} 4$ initial particle size when sintered by microwave on the microstructural, dielectric, and magnetic properties. Applied Ceramic Technology 2019, p. 2073-2084.

[9] Silva, P. B. N. Desenvolvimento de substrato de ferrita para antenas de microfita. Trabalho de conclusão de curso de graduação. UFERSA, Mossoró, 2018.

[10] Castro, K. V. O. Antenas de Microfita Sobre Substrato de Ferrita de Níquel Sopadas com Zinco. Dissertação (Mestrado), UFERSA, Mossoró, 2018.

[11] Fu, M.; Jiao, Q.; Zhao, Y.. In situ fabrication and characterization of cobalt ferrite nanorods/graphene composites. Materials Characterization 2013, 303-315. 